\title{
A CRÍticA DE Frege A TEORIA DA VERDADE COMO CORRESPONDÊNCIA ${ }^{1,2}$
}

Kariel Antonio Giarolo (UFSM) ${ }^{3}$

karielgiarolo@gmail.com

Resumo: Esse artigo tem como objetivo principal apresentar e discutir a crítica construída por Gottlob Frege contra as tentativas de definição do conceito de verdade, especialmente, a definição de verdade como correspondência. As teorias da verdade como correspondência sustentam que a verdade pode ser definida em termos de uma correspondência entre sentenças, proposições ou pensamentos verdadeiros e fatos. Entretanto, Frege, no artigo póstumo Logic (1897) e, posteriormente, em The Thought (1918), apresentará uma contundente crítica a esse tipo de abordagem. Segundo ele, verdade é um conceito básico, elementar e sui generis, o qual não pode ser definido. Meu trabalho será dividido em três partes: na primeira parte, apresentarei a doutrina que sustenta as teorias da verdade como correspondência e suas teses principais; na segunda parte exponho os argumentos utilizados por Frege em sua crítica; e na terceira discuto a tese fregiana da indefinibilidade da verdade.

Palavras-chave: Frege; verdade; teoria da verdade como correspondência; indefinibilidade.

\section{I - A CONCEPÇÃO DE VERDADE DEFENDIDA PELA TEORIA DA CORRESPONDENNCIA}

A meta central de qualquer teoria da verdade consiste em dar uma explicação ou definição daquilo que se entende pelo predicado 'é verdadeiro' e qual a função que ele desempenha em teorias filosóficas, científicas, lógicas, etc. A pergunta "o que é a verdade?", seja ela uma pergunta ade-

\footnotetext{
${ }^{1}$ Recebido: 21-06-2012/Aprovado: 29-08-2013/Publicado on-line: 17-02-2014.

${ }^{2}$ Gostaria de agradecer ao Professor Dirk Greimann pelas orientações antigas e pela ajuda nas discussões sobre Frege.

${ }^{3}$ Kariel Antonio Giarolo é Doutorando em Filosofia pela Universidade Federal de Santa Maria, Santa Maria, RS, Brasil.
} 
quada ou não, recebeu ao longo da história da filosofia uma série de respostas, muitas vezes totalmente discordantes entre si. Embora não haja conformidade nas respostas dadas ao problema, um grupo semelhante delas merece destaque especial. Essas respostas procuram explicar o conceito de verdade de uma maneira bastante intuitiva, em termos de uma relação de correspondência entre sentenças, afirmações, proposições, crenças, etc. e a realidade. As tentativas de responder a pergunta posta por meio desta relação são unificadas dentro de uma teoria geral, chamada de teoria da verdade como correspondência.

Em linhas gerais ${ }^{4}$, a versão mais simples da teoria da verdade como correspondência considerará que uma sentença, proposição ou o que quer que seja é verdadeira quando ela corresponde a um fato, sendo que este fato é algo no mundo que torna a sentença ou proposição em questão verdadeira. Essa teoria requer duas coisas fundamentais: proposições ou sentenças como as coisas que podem ser verdadeiras ou falsas, atuando, portanto, como portadores de verdade (truthbeares) e fatos como coisas no mundo (entidades não linguísticas), ou seja, como fazedores de verdade (truthmakers). Deste modo, uma definição bastante simples diria que 'p' é uma sentença ou uma proposição verdadeira porque p. Por meio desta definição, uma sentença como 'A neve é branca' é verdadeira simplesmente porque a neve é branca. Há um fato no mundo, o fato que a neve é branca, que torna a sentença 'A neve é branca' verdadeira.

\footnotetext{
${ }^{4}$ Tarski (2006), por exemplo, tem uma teoria da verdade como correspondência, mas não a definirá em termos de fato. A concepção semântica da verdade de Tarski irá assumir que verdade é um conceito semântico e que pode ser definida em termos de outros conceitos semânticos, como o conceito de satisfação. A sua teoria da verdade não leva em conta fatos, ela é neutra com respeito a questões metafísicas. Assim, essa posição sobre a teoria da verdade como correspondência não é aceita por todos os autores.
} 
Uma definição de verdade que parte de tais pressupostos necessita esclarecer uma série de tópicos. $\mathrm{O}$ núcleo de uma teoria da correspondência deve discutir 4 pontos fundamentais ${ }^{5}$ : (1) como sentenças correspondem ao mundo; (2) como proposições correspondem ao mundo; (3) a natureza de proposições; e (4) a natureza de fatos. Com isso, consequentemente, adentra-se em um âmbito ontológico, visto que há a necessidade de mexer com o mobiliário básico do mundo ${ }^{6}$.

Entretanto, uma apresentação geral desta teoria esbarra no problema de não haver total concordância no tratamento dos pontos centrais. Destarte, é preciso fazer algumas escolhas e focar em alguns alvos mais específicos. Para os objetivos deste trabalho, isto é, no que tange a Frege, a ênfase deve ser dada à noção de correspondência e, principalmente, à concepção de fato defendida pela teoria. Passemos, portanto, primeiro a uma explicação geral da noção de correspondência e, em seguida, a uma explicação da noção de fato.

Segundo Kirkham (2003), Newman (2002) e, em parte, David (1994), é possível dividir as teorias da correspondência em dois grupos, baseando-se em diferentes noções de correspondência: por um lado, correspondência como congruência e, por outro lado, correspondência como correlação. As teorias da correspondência associadas ao primeiro grupo irão alegar basicamente que há uma espécie de iso-

\footnotetext{
${ }^{5}$ Cf. Newman (2002).

${ }^{6}$ David (1994), de modo similar, defenderá que a construção de uma teoria da verdade como correspondência requer uma explicação ontológica de fatos e uma explicação semântica da relação palavra-mundo (word-to-world). Young (2002 defende, por sua vez, que qualquer análise do conceito de verdade deve conter uma explicação acerca dos portadores de verdade (statements), uma explicação acerca dos fazedores de verdade (facts) e, por fim, especificar a relação entre eles (correspondence).
} 
morfismo estrutural entre os portadores de verdade e os fatos quando o portador de verdade é verdadeiro. Devido a esse isomorfismo, é possível dizer se o portador de verdade corresponde ou não ao fato. Conforme Kirkham (2003, P. 173), “a estrutura das crenças (proposições, sentenças ou o que quer que se tome como portador de verdade) retrata ou reflete a estrutura dos fatos".

A correspondência como correlação, por outro lado sustenta que todo o portador de verdade está correlacionado com um estado de coisas. Não existe nesse segundo grupo de teorias da correspondência um isomorfismo estrutural como no anterior. Se o portador de verdade estiver correlacionado com o estado de coisas, então ele é verdadeiro, caso contrário é falso. $\mathrm{O}$ portador de verdade não reflete a estrutura do estado de coisas, ele simplesmente correlaciona-se com ele de alguma maneira. Contudo, "a correlação é resultado de convenções linguísticas, que são elas mesmas o resultado do desenvolvimento histórico da linguagem” (KIRKHAM 2003, P. 173-174). Verdade, assim como sustenta Austin (1970), é completamente convencional.

Mas, independentemente das diferenças entre os dois grupos, correspondência como correlação e correspondência como congruência, ambos defendem que certas condições necessárias e suficientes para a verdade devem ser satisfeitas. Essas condições são: primeiro, a existência de fatos ou estados de coisas independentes da mente, e, segundo, que haja uma conexão entre o portador de verdade e o fato.

Deparamo-nos, consequentemente, com a noção muito provavelmente mais cara à teoria da verdade como correspondência: a noção de fato. $\mathrm{O}$ que são estes pretensos fatos, 
os quais são os correspondentes dos portadores de verdade? E por que eles devem ser tomados, dentro das teorias da correspondência, como fazedores de verdade (truthmakers)? A resolução destas questões é absolutamente essencial para se compreender os aspectos fundamentais das críticas que podem ser construídas contra as teorias da verdade como correspondência.

Versões bastante simples da teoria da verdade como correspondência assumem, por exemplo, que proposições ou sentenças são portadores de verdade e que para cada proposição/sentença verdadeira existe um único fato (single fact) no mundo com o qual ela corresponde e que a faz (makes it) verdadeira. Entretanto, é necessário dar uma explicação do status ontológico desses fatos. Primeiramente, há duas abordagens acerca da natureza dos fatos: uma abordagem composicional de fatos e uma visão linguística?

A abordagem composicional assume que existem certas coisas reais e considera que um fato é obtido a partir da união de tais coisas. Como consequência, um fato, por ser composto por unidades reais, também seria uma espécie de unidade real. Esta visão de fatos é considerada como a visão clássica e pode ser atribuída a Russell, Wittgenstein e Armstrong. Em Armstrong (1997) isso se encontra de maneira extremamente clara.

Armstrong (1997) afirmará que estados de coisas (Armstrong usa está terminologia ao invés de fato) são compostos. Contudo, para explicitar a composição dos estados de coisas, Armstrong apela para a doutrina fregiana da insaturação de conceitos. Frege, em On Concept and $\mathrm{Ob}$ ject, realiza uma distinção entre objetos e conceitos. As pri-

${ }^{7}$ Cf. Newman (2002, P. 8) 
meiras entidades são saturadas, ou seja, não necessitam de complementação, enquanto que os conceitos são insaturados, necessitam de algo que os complemente. Nesse contexto, para Armstrong, um estado de coisas como 'a sendo F' seria dividido em duas partes: a como um particular e $F$ como a propriedade universal tida por $a$. '__ sendo $F$ ' seria uma apresentação adequada de um universal. Esse universal é chamado de estado de coisas tipo (state-of-affairs type), e a inserção de um particular nesta estrutura insaturada daria origem a uma entidade complexa, isto é, daria origem a um fato.

A visão linguística dos fatos, por outro lado, parte de certas expressões linguísticas e destaca algumas delas na explicação de sua forma linguística como descrevendo estados de coisas. Os estados de coisas seriam introduzidos simplesmente como as entidades descritas por tais expressões. Austin, segundo Newman (2002, P. 140), pode ser aproximado dessa visão linguística dos fatos.

Embora essa distinção entre duas abordagens acerca dos fatos seja de certo modo esclarecedora, ainda não fica claro qual o status ontológico dos fatos. Normalmente, as concepções de fato sustentadas pelas teorias da correspondência irão afirmar que fatos são unidades reais, no sentido de serem eles mesmos coisas com poderes causais. Fatos, então, seriam particulares como coisas ordinárias e habitariam o reino espaço temporal. Na perspectiva de Newman (2002), os fatos parecem ser as entidades adequadas para serem os fazedores de verdade. Para toda sentença existe um fato e, em virtude deste fato, a sentença é verdadeira. Mas há motivos para se suspeitar de fatos como fazedores de verdade, posto que a noção de correspondência parece ser artificial. Contudo, Armstrong (1997) apresenta um argu- 
mento para a existência de estados de coisas (fatos) e, de certo modo, justifica seu papel como fazedores de verdade. $\mathrm{O}$ argumento é chamado de truth-maker argument (argumento do fazedor de verdade).

$\mathrm{O}$ argumento consiste basicamente no seguinte: toma-se o caso de um particular $a$ que instancia um universal $F$, isto é, 'a é F'. A primeira tese posta por Armstrong é que deve haver algo no mundo que torne essa sentença verdadeira, que sirva como o que ele chama de fundamento ontológico para sua verdade. Primeiramente, a deve ser excluído desse papel, uma vez que a é tomado simplesmente como um particular à parte de suas propriedades. Poder-se-ia pensar que o par a e $F$ desempenharia o papel em questão. Contudo, mesmo indo na direção certa, segundo Armstrong, seria possível pensar em $a$ e $F$ como existentes e ainda assim $a$ não sendo $F$. " $F$ pode ser instanciado em outro lugar" (ARMSTRONG 1997, P. 115). Para que ' $a$ é F' seja verdadeira, há a necessidade de algo que faça com que isso seja verdadeiro e este algo deve ser alguma unidade no mundo. O melhor e mais óbvio candidato é o estado de coisas de $a$ sendo F. Nesse estado de coisas (fato), a e F são unidos ${ }^{8}$. A aceitação do truth-maker argument tanto para a existência de estados de coisas, bem como para a aceitação deles como aquilo que faz com que sentenças sejam verdadeiras, não traz consigo, segundo Armstrong, qualquer consequência indesejável ou inaceitável.

Assim, de uma maneira bastante geral, fatos ou estados de coisas são tomados, no interior das teorias da corres-

\footnotetext{
${ }^{8} \operatorname{Dodd}$ (2000, P. 3) define o argumento por meio do seguinte princípio: "Para uma (proposição) 'p' ser verdadeira, existe pelo menos uma entidade, distinta de 'p', cuja existência implica que 'p' é verdadeira”. Este é o chamado princípio TM.
} 
pondência, como unidades reais e, por conseguinte, como fazedores de verdade. Esta é a posição comumente defendida pelos teóricos da correspondência. Sentenças ou proposições verdadeiras corresponderiam a fatos e estes fatos, como entidades no mundo, tornariam as sentenças ou proposições verdadeiras. Há, não obstante, uma série de críticas construídas contra a teoria da correspondência e uma série de problemas adicionais que ela deve resolver, principalmente com respeito à falsidade, mas tais discussões necessitariam de um espaço muito maior do que o disponível. Passo agora a apresentação e discussão da crítica que Frege constrói a esta tentativa de definir o conceito de verdade.

\section{II - A CRÍtICA DE FREGE À TEORIA DA VERDADE COMO CORRESPONDENNCIA}

Um dos aspectos mais importantes da concepção fregiana de verdade diz respeito a sua rejeição da tese de que este conceito possa de alguma maneira ser definido. Essa posição de Frege tem como alvo qualquer tentativa de definir verdade, mas, especialmente, a teoria da verdade como correspondência. Em Logic e em The Thought, é possível encontrar os principais argumentos de Frege contra a possibilidade de definição do conceito. Além disso, na literatura secundária há uma vasta discussão sobre esse tema, ressaltando, principalmente, a parte final do argumento de Frege, a saber, o argumento do regresso. Essas discussões são encontradas, por exemplo, em Dummett (1973), Soames (1998), Ricketts (2005), Levine (2005) e Sluga (2005). Buscarei reconstruir, primeiramente, a critica de Frege localizada nos dois textos citados para, em seguida, apresentar a discussão na bibliografia. 
Dentro da concepção fregiana de lógica, o conceito de verdade angaria um status muito especial. Tanto em Logic como em The Thought, Frege enfatiza a centralidade que esta noção possui. Para a lógica, verdade é tão importante e central como são para a Ética e a Estética os conceitos de Bem e de Belo. E, nesse sentido, "a palavra 'verdadeiro' assinala o objeto da lógica" (FREGE 1997, 325). Porém, a explicação adequada deste predicado somente pode ser dada através daquilo que Frege denomina 'leis do ser verdadeiro'.

Com isso, a tarefa da lógica consiste em descobrir as leis da verdade, do ser verdadeiro (Wahrsein), diferentemente de outras ciências, como a física ou a química que tem como meta descobrir verdades particulares. As leis da verdade são descritivas, tais como as leis da natureza, não admitindo exceção, são elas que de certo modo nos ensinam como deve ser o pensar logicamente correto. Nesse ponto, contudo, há a necessidade de distinguir entre ser verdadeiro e tomar como verdadeiro, isto é, entre lógica e psicologia. O conceito de verdade não pode ser reduzido a algo psicológico?

Para uma análise adequada do conceito de verdade, é necessário delimitar a que tipo de coisas é possível aplicar o predicado 'verdadeiro'. Na linguagem cotidiana, o predicado de verdade surge em várias situações que, logicamente falando, são irrelevantes. Fala-se, por exemplo, de verdadeiro amigo, sentimento verdadeiro ou, até mesmo, verdade de

\footnotetext{
${ }^{9}$ Segundo Frege, principalmente no Prefácio a Grundgesetze der Arithmetik de 1893, no artigo The Thought de 1918 e na sua resenha ao livro de Husserl, Philosophie der Arithmetik de 1894, um grande mal se abatia sobre a lógica de sua época: o influxo da psicologia. Para a lótica psicologista (ou psicologismo) mais extrema, não há diferença entre ser verdadeiro (Wahrsein) e tomar algo como verdadeiro (Fürwahrhalten). Verdade, tomada do ponto de vista psicologista, tal como apresenta Benno Erdman - alvo de Frege no Prefácio a Grundgesetze -, é associada com o reconhecimento geral por parte dos falantes, não tendo um caráter de objetividade, o qual é indispensável a Frege (1964, P. 13).
} 
uma obra de arte. Além disso, 'verdadeiro', no sentido lógico, não deve ser confundido com 'verídico' ou 'veraz'. Todos estes usos do predicado de verdade são, conforme Frege (1997, P. 326), usos que não constituem o objetivo da ciência.

Em The Thought (1997, P. 326), Frege defende que verdade assume a forma linguística de um adjetivo e é atribuída a imagens, ideias ou representações, sentenças e pensamentos. As sentenças são concebidas como conjuntos de sons falados ou imagens em um papel que carregam um conteúdo objetivo chamado de pensamento (Gedanke). Tais pensamentos são os portadores primários de verdade ${ }^{10}$.

As imagens, por sua vez, objeto perceptível através dos sentidos, podem ser chamadas de verdadeiras quando houver uma intenção ${ }^{11}$, quando ela está no lugar de algo, representando alguma coisa. Do mesmo modo ocorre com as representações que somente podem ser verdadeiras quando corresponderem a algo. Nesse sentido haveria uma espécie de relação de correspondência entre uma imagem ou entre uma ideia e um objeto real. Isso, entretanto seria uma espécie de definição psicologista de verdade.

Contudo, em Logic (1979, p.128), Frege afirma explicitamente que seria inútil empregar uma definição para esclarecer aquilo que se entende pela palavra 'verdadeiro'. Ao se dizer, por exemplo, que uma determinada ideia é verdadeira, no caso dela concordar com a realidade, já necessitaría-

\footnotetext{
${ }^{10}$ Mas nem todas as sentenças podem receber um valor de verdade ou conter um pensamento neste sentido. Sentenças que expressam exclamação, imperativas ou interjeitivas, não podem ser verdadeiras nem falsas.

${ }^{11}$ Michael Dummett (1973, P. 442) afirmará que a verdade de uma pintura é relacional, isto é, podemos dizer que uma pintura é ou não verdadeira se conhecermos o outro termo da relação, a saber, o objeto que ela representa e, além disso, se ela corresponde rigorosamente àquilo que ela pretende representar. $\mathrm{O}$ mesmo pode ser aplicado à abordagem das sentenças.
} 
mos ter em mãos aquilo que pretendemos definir. Essa afirmação contém o núcleo da crítica de Frege à teoria da verdade como correspondência e é retomada por ele de maneira mais clara em The Thought, onde ele apresenta três argumentos (ou um argumento composto de três partes) para a refutação desta teoria. No trecho que segue Frege (1997, p 326-327) apresenta sua crítica:

Podemos, pois, presumir que verdade consiste em uma correspondência entre uma imagem e seu objeto. Mas correspondência é uma relação. Isto porém se choca com o modo habitual de se usar a palavra "verdadeiro", que não é uma palavra relacional e nem contém nenhuma indicação de nada com o qual algo deva corresponder. Se ignoro que uma imagem é suposta representar a Catedral de Colônia, então não sei com que comparar esta imagem a fim de decidir sobre sua verdade. Uma correspondência só pode ser perfeita quando as coisas em correspondência coincidem; quando não são coisas distintas. Para verificar a autenticidade de uma cédula é preciso superpô-la a uma cédula autêntica. Mas seria ridículo tentar superpor uma moeda de ouro a uma cédula de vinte marcos. A superposição de uma coisa por uma ideia só seria possível se a coisa fosse também uma ideia. E se a primeira correspondesse perfeitamente à segunda, então ambas coincidiriam. Ora, isto é justamente o que não se quer, quando se define a verdade como a correspondência entre uma ideia e um objeto real. Pois é absolutamente essencial que o objeto real seja distinto da ideia. Mas se assim for, não pode haver correspondência perfeita, verdade perfeita. Assim sendo, nada seria verdadeiro, pois o que é apenas parcialmente verdadeiro não é verdadeiro. A verdade não admite um mais ou menos. Ou será que admite? Não se poderia estabelecer que há verdade quando a correspondência se dá sob determinado aspecto? Mas sob qual aspecto? O que deveríamos fazer, então para decidir se algo é verdadeiro? Deveríamos investigar se é verdadeiro que, digamos, uma ideia e um objeto real se correspondam segundo o aspecto estabelecido. E, do mesmo modo, novamente nos defrontaríamos com uma pergunta do mesmo gênero que a anterior, e o jogo recomeçaria uma vez mais. Assim malogra qualquer outra tentativa de explicar verdade como correspondência. E malogra também qualquer outra tentativa de definir o ser verdadeiro. Pois numa definição cumpre indicar certas notas característi- 
cas da verdade; e ao aplicá-la a um caso particular surgiria novamente a questão de se é verdadeiro que tais notas são constatadas. E assim nos moveríamos em círculo. Por conseguinte, é provável que o conteúdo da palavra "verdadeiro" seja único e indefinível.

O primeiro argumento utilizado por Frege em sua crítica baseia-se nas diferentes categorias ou mesmo funções lógicas das noções de propriedade e de relação. Ao tomarmos que verdade é uma propriedade ${ }^{12}$ de sentenças ou de ideias e uma sentença ou ideia é dita verdadeira no caso dela corresponder a algo, então nos deparamos com um problema. Uma propriedade, apesar de Frege não dizer isso, é uma qualidade intrínseca ou extrínseca de objetos, uma qualidade especial de algo. Na sentença 'a neve é branca' a qualidade de ser branca representa uma propriedade da neve. Nas sentenças onde são expressas propriedades encontramos apenas um lugar vazio, como por exemplo, 'a neve é x', ou ' $x$ da neve' onde ' $x$ ' deve ser completado com algo, no caso 'branca' ou 'a brancura', respectivamente. Em uma relação, diferentemente, está se fazendo uma vinculação entre duas coisas. Relacionar coisas é vinculá-las entre si, e, nesse sentido, é possível falar em correspondência entre dois objetos distintos. Ao dizer 'João é mais velho do que Pedro', construímos uma relação entre dois objetos, João e Pedro. Em uma relação, temos dois lugares vazios que necessitam de complemento: ' $\mathrm{x}$ é mais velho do que y' ou 'x corresponde a y' são exemplos de relações. Na visão de Frege, correspondência assume a característica de ser uma relação.

Por meio desta distinção entre propriedade e relação, Frege edifica o seu primeiro argumento contra as teorias da

\footnotetext{
${ }^{12}$ Para Frege, o predicado 'verdadeiro' não é um predicado no sentido tradicional. Mesmo assim, de um ponto de vista metodológico, ele assume essa posição para tentar mostrar os erros da teoria da correspondência.
} 
correspondência. Soames (1998) apresenta o argumento de Frege de uma maneira bastante simples, afirmando que sua conclusão aplica-se não apenas a pinturas, mas também a outros portadores de verdade, como sentenças e proposições. O argumento é construído por Soames (1998, P. 24) do seguinte modo:

1. Gramaticalmente, 'verdadeiro' é um predicado aplicado a objetos individuais e deve referir-se a uma propriedade, se ele refere-se a algo.

2. Correspondência é uma relação tida entre pelo menos dois objetos.

3. Assim, verdade não é correspondência - isto é, a palavra 'verdadeiro' não expressa (not stand for) qualquer relação de correspondência (posto que ela não expressa nenhuma relação).

Dito de outra maneira, gramaticalmente a palavra 'verdadeiro' é um adjetivo e os adjetivos são modos de atribuição de uma propriedade. Como correspondência não é uma propriedade, e sim uma relação, verdade não pode, consequentemente, consistir em correspondência. 'X corresponde a y' funciona como um predicado relacional, da mesma maneira que 'João é mais velho do que Pedro'. Por outro lado, nas sentenças 'é verdade que $x$ ' ou 'a sentença $x$ é verdadeira', faz-se uso de predicados que somente possuem um local livre.

Embora a conclusão do argumento seja correta, ela não tem força contra as teorias da verdade como correspondência. Para Soames (1998, P. 24), as teorias da correspondência, sejam elas corretas ou não, não são afetadas por esse argumento de Frege porque 'verdadeiro' não quer dizer 
'corresponder a', ou que esta propriedade é idêntica à relação de correspondência. $\mathrm{Na}$ verdade, essas teorias irão defender que verdade é uma propriedade relacional, ou seja, a propriedade de corresponder a alguma coisa na realidade. Um exemplo disso ocorre quando se diz 'x é pai'. Nesse caso, ser pai é uma propriedade, mas uma propriedade relacional, uma vez que todo pai é pai de alguém. A propriedade de ser pai, conforme Soames (1998, P. 24), não é idêntica à relação de paternidade, posto que a primeira é associada a indivíduos e a segunda, a pares de indivíduos. Nas teorias da correspondência aconteceria algo similar entre verdade e correspondência, e isso enfraquece o argumento de Frege.

Entretanto, parece que o próprio Frege percebeu a fraqueza do argumento ao tomar, metodologicamente, na sequência de The Thought, que verdade poderia consistir em correspondência. Nesse ponto, ele entra no seu segundo argumento, que é uma reductio ad absurdum. Assume a posição defendida pelos teóricos da correspondência e leva essa posição às últimas consequências na tentativa de refutá-la. Esta reductio ad absurdum funda-se em uma distinção entre dois tipos diferentes de correspondência: por um lado, uma correspondência perfeita e, por outro lado, uma correspondência apenas parcial. A correspondência perfeita parece ser um tipo de correspondência como congruência, pois assume que as entidades necessitam ter uma estrutura idêntica. A correspondencia parcial, por sua vez, possivelmente estaria vinculada com uma correspondência como correlação, uma vez que ela não necessita que a relação de correspondência implique um isomorfismo estrutural.

Assim, a primeira espécie de correspondência deveria supor que a verdade de uma sentença $p$, por exemplo, somente poderia ser alcançada se $p$ fosse idêntica ao fato com 
o qual ela devesse corresponder. Entretanto, p e o fato com o qual esta sentença corresponde são coisas diferentes. Uma correspondência para ser perfeita necessitaria que as duas entidades em questão pertencessem ao mesmo plano, ou seja, fossem ambas sentenças ou ambas fatos. O exemplo utilizado por Frege (FREGE 1997, P. 327) para aclarar esse ponto é aquele da tentativa de determinação da autenticidade de uma cédula. Para determinar se uma cédula é autêntica, seria preciso compará-la, superpô-la a outra cédula, a uma cédula cuja autenticidade é garantida. Não faria sentido, contudo, compará-la a algo distinto dela, tal como uma moeda. Consequentemente, de acordo com a definição de correspondência, verdade não pode ser perfeita, uma vez que há a necessidade de que os objetos que entram nessa relação sejam objetos distintos. "Uma verdade supostamente é distinta do fato que ela corresponde" (SOAMES 1997, P. 24).

Por outro lado, se tomarmos verdade como sendo apenas parcial, defrontamo-nos com outra questão que para Frege é bastante significativa. $O$ conceito de verdade não é algo que admite graus: ou uma sentença assertiva completa é verdadeira, falsa ou não tem valor de verdade. Não faria sentido, dentro de sua concepção lógica, falar de sentenças que são parcialmente verdadeiras. "... o que é parcialmente verdadeiro não é verdadeiro. A verdade não admite um mais ou menos" (FREGE 1997, p.327) ${ }^{13}$.

Com isso, verdade como correspondência não poderia nem ser perfeita, já que isto implicaria identidade, e nem ser parcial, pois Frege assume que este conceito é simples, primitivo e não admite qualquer graduação. Apesar disso,

\footnotetext{
${ }^{13}$ No escrito póstumo Logic de 1897 (1979, P. 126) já encontramos essa tese.
} 
Frege indaga se não haveria a possibilidade de pensar verdade acontecendo sob um determinado aspecto, ou seja, pensar que uma ideia e um objeto real ou uma sentença e um fato correspondessem sob um ponto de vista específico. Essa suposição dá origem à parte final da argumentação fregiana contra as teorias da correspondência e é denominada pela maioria dos autores, como já foi dito, argumento do regresso. Tal argumento é reconstruído por vários autores da literatura. Tomo como base Soames (1998) - que afirmará que o argumento segue por dois caminhos: um enfatizando regresso e o outro, circularidade -, Ricketts (2005) e Dummett (1973). Basicamente, a reconstrução do argumento se assemelha em muito nesses autores, variando em poucos aspectos. O que importa é que eles concordam que qualquer tentativa de definição de verdade como correspondência irá pressupor o conceito que ela busca definir.

Dummett (1973, P. 442-443) afirmará que, na perspectiva de Frege, verdade não pode ser reduzida a outra coisa mais fundamental. Ao se pensar que a verdade de uma determinada sentença possa consistir em algum gênero de correspondência com outra coisa, chamada, por Dummett, de $W$, então, para determinar se esta correspondência é obtida, seria necessário investigar a verdade de outra sentença. Esta sentença adicional seria 'Esta sentença corresponde com $W^{\prime}$. Se a verdade desta última sentença consistisse, por sua vez, em sua correspondência com alguma coisa adicional, $W^{*}$, então, para determinar sua verdade, precisaríamos investigar a verdade da sentença 'A sentença "Esta sentença corresponde com $W^{\prime \prime}$ corresponde com $W^{*}$. Tal situação leva a um regresso ao infinito. Além disso, a verdade de uma sentença não é relacional. Na ontologia fregiana, segundo Dummett (1973, P. 442), fatos não são constituintes 
da realidade, do reino da Bedeutung, mas do reino do sentido. Um pensamento não é verdadeiro somente no caso dele corresponder com um fato. Se ele é verdadeiro, então ele é um fato e não existem duas coisas entre as quais uma comparação deve ser feita a fim de descobrir se elas correspondem.

Ricketts (2005, P. 236) estabelecerá o argumento de modo bastante similar ao de Dummett. Assim como Dummett (1973), Ricketts também afirma que a verdade de ideias ou de imagens, em última instância, é reduzida à verdade de sentenças que expressam pensamentos. A definição de verdade da teoria da correspondência, assim, irá aplicar a definição para determinar, por exemplo, que a ideia representando 'Sócrates é mortal' corresponde com a realidade. Este ato implica, para Ricketts (2005), fazer um juízo, no caso, que certa ideia tem certa propriedade. Fazer isso, entretanto, requer uma segunda aplicação da definição, a saber, a ideia representando a correspondência entre a ideia Sócrates sendo mortal com a realidade. Dito de modo mais simples, para julgar que $p$ é preciso, anteriormente, julgar que $p$ corresponde com a realidade. $E$ isso leva a um regresso.

Ricketts (2005) defende que a crítica de Frege a teoria da correspondência tem como pano de fundo suas disputas com o psicologismo e com o empirismo. A definição de verdade dada pelas teorias da correspondência seria, de certo modo, uma definição psicologista de verdade. Ela tomaria entidades mentais como inseridas na relação de correspondência. A maior motivação que levaria Frege a rejeitar esta definição, para Ricketts (2005, P. 236), consiste na concepção fregiana de juízo, a qual se reflete em sua concepção da própria lógica. No argumento do regresso, a 
concepção de juízo tem um papel fundamental e tiraria a aparência que o argumento é um mero sofisma como defende Dummett (1973, P. 443). Na visão empirista, juízos são conjuntos de representações mentais. Desse modo, a verdade de juízos sobre corpos materiais deveria consistir em alguma concordância entre as representações e os corpos que elas representam. Contudo, conforme Frege (1997, P. 329), um juízo não tem nada de subjetivo, ele consiste no reconhecimento da verdade de um pensamento. $\mathrm{O}$ argumento do regresso, como consequência, teria como meta rejeitar a identificação de pensamentos com alguma série de objetos na ordem espaço-temporal.

Soames (1998, P. 25), por sua vez, reconstruirá o argumento de Frege de duas maneiras diferentes, uma delas realçando o regresso e outra, a circularidade. A primeira maneira se assemelha às reconstruções de Dummett (1973) e Ricketts (2005) e não é necessário repetir. Já a segunda maneira de ver o desenrolar do argumento merece alguma ênfase. Supomos que verdade seja definível e que a definição seja a seguinte: para qualquer proposição p, p é verdadeira se e somente se p é $T^{14}$. Nesse caso, decidir se uma proposição $p$ é verdadeira envolve decidir se a proposição p é T é verdadeira. Contudo, isso é uma definição circular, pois, toda vez que indagarmos pela verdade de uma proposição, sentença ou pensamento $p$, teremos que saber se $p$ é T. Posto que definições não podem ser circulares, conclui-se que verdade é indefinível.

Assim, tem-se de modo razoavelmente claro a estratégia argumentativa de Frege contra as teorias da verdade como correspondência. Na próxima seção, examinarei as críticas

${ }^{14}$ Cf. Soames (1998, P. 24). 
contra o argumento de Frege, principalmente as de Dummett (1973) (1981) (1991) e Levine (2005). Juntamente, será analisada a concepção fregiana de definição encontrada no escrito póstumo Logic in Mathematics de 1914 (Frege, 1979) e em On the Foundations of Geometry: Second Series de 1906 (Frege, 1984). Isso é importante, pois Levine (1996) afirmará que, embora Frege negue que verdade seja definível, ainda seria possível falar em elucidação do conceito

\section{III - A TESE FREGIANA DA INDEFINIBILIDADE DA VERDADE.}

A tese fregiana de que verdade seja um conceito indefinível se assenta em uma divisão entre dois tipos diferentes de conceitos: conceitos simples e conceitos complexos ${ }^{15}$. Conceitos complexos são aqueles conceitos que são constituídos por conceitos simples. Neste sentido, pode-se dizer que os conceitos complexos são capazes de serem definidos em termos de conceitos simples. Um exemplo tirado da matemática poderia ser o conceito 'triângulo'. Temos a possibilidade de analisar ou definir tal conceito por meio das notas características que o constituem: ângulo interno de $180^{\circ}$, três lados, etc.

Por outro lado, temos aqueles conceitos que não podem ser definidos ou analisados em termos de outros conceitos mais básicos. Estes conceitos simples possuem um status especial frente aos outros conceitos. São tão fundamentais e importantes que podem analisar outras coisas, mas não podem ser analisados por outros conceitos e nem mesmo se auto-analisar. $O$ ponto a discutir seria se o conceito de verdade pertence ao grupo dos conceitos simples. A

\footnotetext{
${ }^{15}$ Está divisão não é apresentada por Frege, mas por Soames (1998, P. 24).
} 
resposta dada por Frege (1979, P. 126, 1997, P. 327) é positiva. Verdade é um conceito simples, primitivo, sui generis e indefinível. Contudo, para esclarecer porque o conceito de verdade é indefinível é preciso de antemão esclarecer o que Frege entende por 'definição'.

Em On the Foundations of Geometry: Second Series e, posteriormente, em Logic in Mathematics, Frege afirmará que, para a construção de um sistema de ciência, há a necessidade de determinar as leis de inferência e, por conseguinte, as redes de inferências que suportam todo o sistema. Consequentemente, a procura por verdades primitivas é fundamental. Frege destaca três noções essenciais vinculadas a isto: axiomas, postulados e, principalmente, definições.

Para Frege, uma definição basicamente lida com signos. Em uma teoria ou em um sistema com um propósito científico há a necessidade de termos técnicos que consigam evitar as confusões da linguagem ordinária. Assim, para os fins da ciência, os termos têm de fixar Bedeutung, possibilitando que mal entendidos provenientes do uso ambíguo sejam evitados. A construção de uma ciência rigorosa necessita, por conseguinte, de uma linguagem rigorosa. Um símbolo novo inserido por meio da definição teria como propósito facilitar e simplificar a expressão anterior sem que haja a alteração do conteúdo da mesma.

A questão aqui, com respeito ao conceito de verdade, é que dentro de um sistema científico não é possível alcançar uma definição de verdade. $O$ argumento fregeano do regresso excluiria uma definição de verdade, seja em termos de correspondência, seja por qualquer outra relação possível. Como afirma Levine (2005, p.249), para compreender o argumento de Frege contra a definibilidade da verdade é preciso considerar sua visão de definição e também sua 
concepção de juízo. Em certos sistemas científicos, nem todos os termos podem ser definidos. Aqueles termos mais simples e fundamentais, os quais poderiam ser chamados de 'blocos de construção de um sistema', normalmente não conseguem ser definidos e nem mesmo analisados internamente. Como verdade é um conceito simples e primitivo na concepção fregiana, então, como consequência, não poderíamos definí-lo dentro do sistema.

Mesmo assim, em On the Foundations of Geometry: Second Series, Frege admite que os elementos primitivos constituintes de um sistema, embora indefiníveis internamente, podem ser elucidados do lado de fora do sistema ${ }^{16}$. Lemos neste texto (1984, P. 300):

Nós devemos admitir logicamente elementos que são indefiníveis.... Visto que definições não são possíveis para elementos primitivos, alguma outra coisa deve ser introduzida. Eu chamo isto de elucidação (explication). É isto, portanto, que serve ao propósito de mútua compreensão entre investigadores, bem como para a comunicação da ciência aos outros.

As elucidações teriam um caráter de auxílio na comunicação e compreensão de teorias científicas. Frege (1984, P. 301) enfatizará, logo a seguir, a importância pragmática das elucidações. "O propósito de elucidações é um propósito pragmático; e uma vez que o alcançamos devemos ficar satisfeitos com ele. E aqui, devemos ser capazes de contar com a boa vontade e compreensão cooperativa" (FREGE 1984, P. 301). Como a mútua compreensão é fundamental na ciência, e no que tange a conceitos primitivos não temos definições, então o que nos resta são tentativas de elucida-

\footnotetext{
${ }^{16}$ Levine (2005 P. 249) defende uma posição semelhante. Segundo ele "o argumento do regresso exclui uma definição fregiana de verdade, mas, por si só, não exclui uma 'elucidação' correspondencial de verdade".
} 
ção de tais conceitos. Essas elucidações ou explicações muitas vezes são obscuras e, portanto necessitam de boa vontade e cooperação na compreensão, posto que elas se apresentam por meio de metáforas, modos figurativos de expressão, etc..

Tendo isso em mente, poderíamos pensar que o conceito de verdade admitiria elucidação. Em todas as obras onde Frege discute o conceito de verdade, encontramos características ou peculiaridades que talvez pudessem ser tomadas como elucidações. Contudo, Frege, com seu argumento do regresso, parece excluir a possibilidade de definição de verdade por meio de alguma relação qualquer como também exclui a possibilidade de elucidação de verdade em termos de correspondência. Entretanto, Ricketts (2005) e Levine (2005), possivelmente de um modo correto, defenderão que o argumento de Frege em defesa da tese da indefinibilidade da verdade não sustenta esta conclusão forte e Levine (2005, p 259), inclusive, apelará a Wittgenstein no Tractatus (3.263). Pois, para Wittgenstein, elucidações não se encontram do lado de fora de um sistema. Ao contrário de Frege, que não dá nenhuma indicação de quais elucidações podem ser traduzidas na notação da Begriffsschrift e, portanto que não seriam capazes de dar conta do conceito de verdade, para Wittgenstein poderia se falar em elucidação correspondencial de verdade (embora uma elucidação não possa ser traduzida para a notação lógica do Tractatus).

Dummett (1973) também irá encontrar problemas no argumento do regresso de Frege. De acordo com Dummett (1973, P. 443), o raciocínio de Frege demonstrando que verdade é absolutamente indefinível dá a primeira impressão de ser sofístico. A possibilidade do regresso não tem nada a ver com o fato de verdade ser definível ou não, pois, 
ao tentar descobrir que, por exemplo, a teoria da relatividade é verdadeira, seria necessário perguntar pela verdade da sentença 'A teoria da relatividade é verdadeira' e adicionalmente 'A sentença "A teoria da relatividade é verdadeira” é verdadeira', e assim por diante. Parece claro, para Dummett (1973), que, mesmo se tivéssemos uma definição de verdade, poderíamos construir este tipo de argumento. Além do mais, o próprio regresso não é vicioso. Ele somente será vicioso se, para determinar a verdade de um membro da série, seria desejoso determinar a verdade do próximo membro. Poderíamos nos contentar com 'A teoria da relatividade é verdadeira' e aplicar isso para determinar o valor de verdade de muitas outras sentenças.

Como consequência disso, segundo Dummett (1973, P. 443-444), o argumento de Frege não sustenta que verdade é completamente indefinível. Entretanto, ele consegue ter força contra a definição de verdade sustentada pelas teorias da correspondência. Lemos em Dummett (1973, P. 444)

[...] o regresso infinito pode ser neutralizado desde que o resultado da aplicação da definição de ' ... é verdadeiro' para o exemplo específico “"Frege morreu em 1925" é verdadeiro' seja que esta sentença é reduzida a sentença 'Frege morreu em 1925' e, igualmente, para todos os outros exemplos específicos. ${ }^{17}$

As teorias da verdade como correspondência, porém, não conseguem satisfazer esta condição, pois elas tornam o regresso vicioso, elas sempre procuram por correspondências adicionais. Assim sendo, o argumento de Frege consegue, de certo modo, ter sucesso contra este alvo. Para

\footnotetext{
${ }^{17}$ No original: "the infinite regress can be neutralized provided that the result of applying the definition of '... is true' to the specific instance "Frege died in 1925" is true' is that this sentence is reduced to the sentence 'Frege died in 1925', and likewise for all other specific intances."
} 
Dummett (1973), portanto, a estratégia argumentativa fregiana não é capaz de demonstrar que verdade é indefinível, mas, mesmo assim, ela consegue colocar limitações em várias definições aceitáveis de verdade.

Levine (2005, p.254) concorda com Dummett (1973) sobre os problemas conectados ao argumento do regresso fregeano. Para ele o regresso ao infinito é gerado devido a uma má aplicação da definição, pois em uma definição os termos que constituem o definiens são eliminados ficando-se com o termo novo introduzido. Nesse sentido, uma definição de verdade não seria uma tentativa de introduzir a palavra 'verdadeiro', mas sim de eliminar o uso já corrente da palavra. A noção de verdade, para Frege, já está presente no juízo em que aplicamos a definição. Percebe-se, com isso, que as noções de verdade e juízo estão fortemente ligadas. Para Frege, julgar que $\varnothing$ A (o símbolo ou constante ' $\varnothing$ ', no exemplo de Levine, consiste apenas nos termos introduzidos sem apelar à noção de verdade) é reconhecer que é verdadeiro que $\varnothing \mathrm{A}$.

Na notação da Begriffsschrift (1997, p.52), isso já fica bastante evidente. Um juízo sempre será expresso pelo símbolo ' $\curvearrowleft$ '. Como sabido, este é o primeiro signo introduzido por Frege na Begriffsschrift. ' $\models \varnothing A^{\prime}$ ' quer dizer que o conteúdo de uma proposição ' $\varnothing \mathrm{A}$ ' está sendo asserido como verdadeiro. Tudo aquilo que estiver à direita da barra do juízo está sendo julgado.

Assim, fica manifesto que, toda vez que Frege falar em juízo, ele pressupõe o conceito de verdade. Como a visão fregiana de definição pode ser aplicada apenas a juízos que não pressupõem a noção definida, então não é possível eliminar o conceito de verdade em prol de noções mais básicas. Aplicar a definição de verdade requer fazer um juízo 
que não pressupõe a noção de verdade, e como, para Frege, fazer um juízo pressupõe a noção de verdade, então é impossível uma definição, uma explicação que não seja circular. Ao tomar que as noções de verdade e juízo são conceitualmente ligadas, exclui-se qualquer possível definição de verdade.

$\mathrm{O}$ argumento de Frege em favor da tese da indefinibilidade da verdade exibe, resumidamente, ao menos três características fundamentais de sua concepção de verdade ${ }^{18}$.

Em primeiro lugar, que verdade não é apenas indefinível, mas também é um conceito sui generis. Frege pressupõe que o conceito de verdade é indefinível não porque é pressuposto no conteúdo de um juízo anterior à aplicação da definição, mas porque ele é necessário no ato de julgar algum conteúdo. “... verdade está refletida não em nosso uso da palavra "verdadeiro, mas ao contrário no ato de asserção” (LEVINE 2005, P. 255)

Em segundo lugar, o argumento de Frege não atinge apenas uma característica da teoria da verdade como correspondência em especial, mas também é aplicável a teorias pragmáticas ou coerentistas da verdade. Os mesmos problemas encontrados nas teorias da correspondência podem ser encontrados nestas outras tentativas de definir verdade. O problema nessas teorias é o mesmo: é necessário, para aplicar a definição de verdade, ter de antemão a noção de verdade. $\mathrm{O}$ argumento é dirigido contra qualquer teoria que tente definir verdade.

O terceiro ponto é que o argumento de Frege exclui não só teorias substancialistas da verdade, nas quais verdade é definida por uma propriedade substancial, mas também

\footnotetext{
${ }^{18}$ Isso é encontrado em Levine (2005, P. 257), por exemplo.
} 
teorias da redundância, nas quais o predicado 'é verdadeiro' não faz nenhuma contribuição para o conteúdo das sentenças nas quais ele ocorre. Embora o predicado de verdade na linguagem natural não tenha um conteúdo, sendo, portanto, um predicado supérfluo, o conceito de verdade não é supérfluo na concepção fregiana. Não podemos abrir mão de forma alguma do conceito de verdade e este está contido na própria forma da sentença assertiva.

E esta última afirmação é extremamente fundamental dentro da concepção fregiana de verdade. Para Frege (1997, P. 158), tanto em sentenças que fazem uso do predicado 'é verdadeiro', assim como em sentenças que não o fazem, a asserção da verdade reside na forma da sentença assertiva ${ }^{19}$. $\mathrm{O}$ conceito de verdade, portanto, está intimamente ligado com a força assertiva. Em Logic de 1897, podemos ter uma visão disso (1979, P. 129):

Portanto, é realmente usando a forma da sentença assertiva que asserimos verdade, e, para fazer isso, não precisamos da palavra 'verdadeiro'. De fato, podemos dizer que, mesmo quando usamos a forma da expressão 'é verdadeiro que ...', a coisa essencial realmente é a forma da sentença assertiva.

A tese de que o operador de verdade fundamental encontrado na linguagem natural está na forma da sentença assertiva e não no predicado 'é verdadeiro' parece ser um desdobramento do simbolismo fregeano da Begriffsschrift. $\mathrm{O}$ símbolo '—A' quer dizer que o conteúdo de uma proposição ou sentença 'A' está sendo julgado, ou, poder-se-ia dizer, asserido como verdadeiro. A barra vertical seria a barra

\footnotetext{
${ }^{19}$ Greimann (2005, P. 306) denominará esta doutrina de 'Assertion Theory of Truth'. Para ele, de acordo com tal abordagem, verdade não é nem uma propriedade e nem um objeto, mas uma outra coisa que pertence a mesma categoria que satisfação (satisfaction).
} 
do juízo, ou seja, garantiria a verdade daquele conteúdo que vem a seguir. Na Begriffsschrift (1997, P. 53), Frege irá utilizar a noção de asserção:

A barra horizontal, da qual o símbolo $\longmapsto$ é formado, liga os símbolos que o seguem em um todo, e a asserção, que é expressa pelo significado da barra vertical na extremidade esquerda da horizontal, relaciona este todo. A barra horizontal pode ser chamada barra do conteúdo, a vertical, barra do juízo.

Levine (2005, P. 255) parece ter uma interpretação parecida. Verdade surge, na Begriffsschrift, na barra vertical. É por meio deste símbolo que expressamos a asserção e, consequentemente, a verdade de uma determinada sentença. Greimann (2005) clarificará ainda mais a relação entre a barra vertical e a asserção ao afirmar que a contraparte da barra do juízo, da barra vertical, na linguagem natural encontra-se na forma da sentença assertiva. "Enquanto que '$F(a)$ simplesmente expressa o pensamento que $a$ é $F$ sem dizer se o pensamento é verdadeiro ou falso, ' $\vdash F(\mathrm{a})$ ' expressa que o valor de verdade deste pensamento é o Verdadeiro" (GREIMANN 2005, P. 309). Ao longo de suas obras, Frege irá apresentar uma série de teses acerca do problema da verdade, mas quando, em The Thought, ele apresenta a tese da indefinibilidade da verdade, ele retoma uma ideia contida na Begriffsschrift de que o juízo tem uma primazia ${ }^{20}$. Logo, é na forma da sentença assertiva que asserimos verdade.

\section{IV - CONSIDERAÇÕES FINAIS.}

Mas quais são as conclusões que podem ser tiradas dessa

\footnotetext{
${ }^{20}$ Para ter uma ideia mais clara do desenvolvimento da concepção fregiana de verdade, ver Sluga (2005).
} 
crítica de Frege e qual é, em última instância, a sua concepção de verdade?

Em primeiro lugar, Frege não apresenta concepção clara e muito menos sistemática de verdade. Em segundo lugar, embora esse conceito seja fundamental dentro de sua lógica e de sua filosofia, aquilo que podemos encontrar em suas obras são teses predominantemente negativas acerca dele. A crítica à teoria da verdade como correspondência também faz parte dessa concepção negativa. Frege ao elaborar a crítica tem como alvo o psicologismo, uma vez que, a definição de verdade como correspondência é, para ele, uma definição psicologista de verdade. Entretanto, a crítica não diz nada positivo sobre a natureza do conceito de verdade. $\mathrm{O}$ que fica explícito é que verdade não pode ser definida e que as tentativas de definição, especialmente por meio da correspondência, caem na tão terrível terra do psicologismo.

Além disso, apesar de Dummett (1973) assumir que a crítica fregiana impõe limitações a certas definições de verdade, temos que ter em mente que é uma crítica muito fraca. A teoria tarskiana da verdade (que é uma espécie de teoria da correspondência), por exemplo, não poderia ser refutada pelos argumentos de Frege, uma vez que fatos ou estados de coisas não desempenham papel fundamental na teoria. E mesmo teorias clássicas da correspondência sobreviveriam à estratégia argumentativa de Frege. A afirmação de Soames de que verdade é uma propriedade relacional corrobora tal ponto. Outro ponto importante é que, apesar de Frege sustentar que verdade dentro de um sistema de ciência é um conceito básico e, portanto, indefinível, isso não implica que não possamos dar certas explicações ou elucidações desse conceito. Ao afirmarmos ou negarmos que 
verdade é isto ou aquilo estamos de alguma maneira contribuindo para uma compreensão do conceito. $O$ propósito pragmático, constituinte de uma elucidação, como apresentado em On the Foundations of Geometry: Second Series, está sendo levado em conta.

Em suma, a crítica à teoria da verdade como correspondência, a despeito de seu discutível alcance e sucesso, lança as bases para a sustentação da tese que talvez seja a mais forte candidata a ser a concepção de verdade defendida por Frege que é, justamente, a tese de que verdade é dada pela forma da sentença assertiva. O predicado 'é verdadeiro' e uma definição de verdade não seriam fundamentais para sustentar essa tese.

Abstract: This paper has as main objective present and discuss Gottlob Frege critic to the attempt to define the concept of truth, especially, the attempt to define of truth as correspondence. The correspondence theories of truth sustain that truth can be defined in terms of correspondence between sentences, propositions or true thoughts and facts. However, in his posthumous writing Logic (1897) and, after, in The Thought (1918), Frege presents a severe critic to this kind of approach. He holds that truth is a basic, simple and sui generis concept, which cannot be defined. My paper will be divided in three parts: in the first part, I will present the doctrine that sustains the correspondence theories of truth and his main theses. In the second part, I will expose the arguments used by Frege in his critic; and in the third, and lastly part, I will discuss the Fregean thesis of the indefinability of truth.

Keywords: Frege; truth; correspondence theory of truth; indefinability.

\section{REFERÊNCIAS}

ARMSTRONG, D. A World of States of Affairs. Cambridge: Cambridge University Press, 1997.

AUSTIN, J. Philosophical Papers. Ed. by J. Urmson and G. Warnock. Oxford: Clarendon Press, 1970.

DAVID, M. Correspondence and Disquotation. An Essay on 
the Nature of Truth. New York: Oxford University Press, 1994.

DODD, J. An Identity Theory of Truth. Chippenham and Eastbourne: Palgrave Macmillan, 2000.

DUMMETT, M. Frege. Philosophy of Language, London, Harper and Row, 1973.

FREGE, G.. The Thought. The Frege Reader. Ed. by M. Beaney. Oxford: Blackwell, 1997, 325-345.

. The Frege Reader. Ed. by M. Beaney. Oxford: Blackwell, 1997.

. Posthumous Writings. Ed. por H. Hermes, F. Kambartel e F. Kaulbach, e trad. por P. Long and R. White, Oxford: Basil Blackwell. Trad. inglesa de G. Frege, Nachgelassene Schriften und Wissenschaftlicher Briefwechsel, Band 1, ed. por H. Hermes, F. Kambartel e F. Kaulbach, Hamburg: Meiner, 1979.

. Lógica e Filosofia da Linguagem. Trad. Paulo Alcoforado. São Paulo: Edusp, 2009.

. The Basic Laws of Arithmetic. Exposition of the System. Trad. Montgomery Furth. Los Angeles: University of California Press, 1964.

GREIMANN, D. Frege's Understanding of Truth. In. Gottlob Frege. Critical Assessment of Leading Philosophers. Ed. by M. Beaney and E. Reck. Vol. II. London: Routledge, 2005, p. 295-314.

KIRKHAM, R. Teorias da Verdade. Uma Introdução Crítica. São Leopoldo: Editora Unisinos, 2003. 
KIRKHAM, Richard. Theories of Truth. A Critical Introduction, Cambridge/M., MIT Press, 1992.

LEVINE, J. Logic and Truth in Frege. In. Gottlob Frege. Critical Assessment of Leading Philosophers. Ed. by M. Beaney and E. Reck. Vol. II. London: Routledge, 2005, p. 248-269.

- Analysis, Abstraction Principles and Slingshot Arguments. Ratio, XIX, 2006, p. 43-63.

NEWMAN, A. The Correspondence Theory of Truth. An Essay on the Metapysics of Prediction. Cambridge: Cambridge University Press, 2002.

NEALE, S. Facing Facts. Oxford: Clarendon Press, 2001.

RICKETTS, T. Logic and Truth in Frege. In. Gottlob Frege. Critical Assessment of Leading Philosophers. Ed. by M. Beaney and E. Reck. Vol. II. London: Routledge, 2005, p. 121-140.

SLUGA, Hans. Frege on the Indefinability of Truth. In. Gottlob Frege. Critical Assessment of Leading Philosophers. Ed. by Michel Beaney and Erich H. Reck, Vol. 2. London: Routledge, 2005, 270-294.

SOAMES, S. Understanding Truth. New York: Oxford University Press, 1998.

TARSKI, A. A concepção Semântica da Verdade. Trad. Braida, et. all. São Paulo: Unesp, 2006.

WITTGENSTEIN, L. Tractatus Lógico-Philosophicus. Trad. Luiz Henrique Lopes dos Santos. São Paulo: Edusp. 2001. 
YOUNG, J. The Slingshot Argument and the Correspondence Theory of Truth. Acta Analytica. Vol. 17 - Issue 29, 2002, p. 121-132. 